\title{
IMPROVEMENT OF BUS VOLTAGE PROFILES OF NIGERIAN POWER NETWORK IN THE PRESENCE OF STATIC SYNCHRONOUS COMPENSATOR (STATCOM) AND DOUBLY FED INDUCTION GENERATOR (DFIG)
}

\author{
I. B. Anichebe $1, *$ and A. O. Ekwue ${ }^{2}$ \\ 1, DePARTMENT OF ElECTRICAL ENGINEeRING, UNIVERSITY OF NigERIA NsUKKA, ENUGU STATE, NIGERIA \\ 2, JACOBS ENGINEERING INC. LONDON, UNITED KINGDOM \\ E-mail addresses: 1ifebenny@yahoo.co.uk, 2arthur.ekwue@gmail.com
}

\begin{abstract}
Frequent blackouts and unstable supply of electricity show that the voltage instability problem has been one of the major challenges facing the power system network in Nigeria. This study investigates the voltage stability analysis of the Nigerian power network in the presence of renewable energy sources; FACTS device is used as a voltage controller. A 330kV, 28-bus power system network was studied using the PSS/E software-based Newton-Raphson load-flow technique. The results show that 10 out of the 28 buses had voltages /ying below the statutory limit of $0.95 \leq 1.05$ p.u. The application of STATCOM and DFIG devices on two of the weakest buses restored the voltages to acceptable statutory limits. The total active and reactive power losses were reduced to $18.76 \%$ and $18.82 \%$ respectively.
\end{abstract}

Keywords: Voltage stability analysis; Integration of renewable energy sources; FACTS controllers, Reactive Power, Power Flow.

\section{INTRODUCTION}

The operating condition of any power system is meant to be in a stable condition and should meet satisfactory operating criteria: the network should be secured in the event of any credible contingency. A power system is said to be in the state of voltage instability when there is a progressive or uncontrollable drop in voltage magnitude after a disturbance or increase in load demand or any significant change in operating condition such as the exhaustion of reactive reserves in the system. Several definitions have been given to voltage instability. It can be defined as "a phenomenon by which the receiving end voltage decreases well below its normal value and does not come back even after setting restoring mechanisms such as VAR compensators, continue to oscillate for lack of damping against the disturbances" [1]. Voltage collapse on the other hand is the process by which the voltage falls to a low value, unacceptable value because of an avalanche of events accompanying voltage instability [1]. Voltage stability assessment is an important issue in the operation and planning of modern power systems [2]. The voltage instability has been given attention by the power system community and it is usually referred to as the inability of a power system to maintain steady acceptable voltages at all buses under normal operating conditions or after being subjected to any perturbation [3]. Both the IEEE and CIGRE professional associations have their respective definitions [4]. It can thus be interpreted as the capability of the power system to maintain equilibrium at reasonable voltage levels. The principal factors contributing to voltage collapse are generator active power / voltage control limits, load characteristics, characteristics of reactive compensation devices, and the action of voltage control devices such as transformer under load - tap changers (ULTCS). The main factor causing voltage instability is the inability of the system to meet the demand for reactive power (Q) under normal operating conditions, the bus voltage magnitude $(\mathrm{V})$ increases as reactive power $(\mathrm{Q})$

* Corresponding author, tel: +234 8071717419 
injected at the same bus is increased. However, when voltage magnitude (V) of any of the system's buses decreases with the increase in the reactive power (Q) for the same bus, the system is said to be unstable. Although the voltage instability is a localized problem, its impact on the system network can be wide spread as it depends on the relationship between transmitted active power $(P)$, injected reactive power $(Q)$ and receiving end voltage $(\mathrm{V})$. These relationships play a vital role in the stability analysis [5]. Analytical techniques for voltage stability analysis have been under investigation with a hope of providing better tools for operational planning and system control [6]. Voltage instability problem has been a vital operational concern of electrical power systems because it is the main cause of power blackout in many developing countries such as Nigeria. The implementation of voltage stability analysis becomes paramount to make sure that the voltage level at all buses is at stable state [7]; this is the motivation for this study.

The quest for clean energy source, environmental effect and depletion of fossil fuel resources as well as the growing concern of greenhouse gases enhances the investment and development of renewable energy resources (wind and solar resources) by many countries as alternative to power sources [8]. However, the rapid growth in using renewable energy sources poses challenges for system network and operators. These challenges include system security, power quality and system stability. Among renewable energy sources, wind power generation has been experiencing rapid development. The size of a wind turbine and wind farms are increasing and a large amount of wind power is being integrated into the power system network. As its penetration into the network increases the influence of wind turbines on the power quality and voltage stability is becoming more and more important [9]. For instance, if large wind farms are connected to a transmission network, transient stability problems could occur which may result in the disconnection of many wind generators. But if a smaller installation is connected to distribution network, power quality and voltage dip problems may occur because of the proximity to the loads [10]. Therefore, if sufficient reactive power compensators are not available, a voltage instability situation may occur. More so, issues like loadability limit of the network, fault ride through capability, reactive power reserve and time response of these reserves all forms the voltage stability studies [9].
Nigeria is faced with series of operational problems, fundamentally, poor quality power supply, voltage instability and high transmission loss. The traditional methods such as synchronous generator series compensation capacitor, generator excitation regulation, magnetically controlled reactor, etc have been in use but respond slowly, causes wear and tear in the mechanical components and become undesirable and economically viable. Alternatively, the use of power electronics-based technology called FACTS which is fast acting and cost effective has been advocated [11]. It has been widely noted that the advances in power electronics with their sophisticated control techniques enhances the development of FACTS.

FACTS represent the most efficient combination of conventional primary equipment, high power semiconductor devices, microelectronics and telecommunications equipment [12]. Thus, the power system network can be modified to alleviate voltage instability or collapse by adding reactive power sources at the appropriate locations. Various FACTS devices available for this purpose, include Static VAR Compensator (SVC), Thyristor Controlled Series Capacitor (TCSC), Static Synchronous Series Compensator (STATCOM) and Unified Power Flow Controller (UPFC). The concepts of FACTS were first introduced in [13]. These devices not only have the capability in controlling active and reactive power flow but also can redistribute power flow even under highly loaded condition thereby reducing overall congestion. Hence, FACTS controllers can be used to increase system loadability as situation demands, enabling utilities to get the most services from their transmission facilities and enhancing grid reliability. FACTS make it possible that current through a line can be controlled, increasing the capacity of existing lines and enable corresponding power to flow through such lines under normal and contingency conditions [14]. The FACTS controllers have the ability to control the interrelated parameters that govern the operation of transmission systems viz; series impedance, shunt impedance, current, voltage, and phase angle. Additional of flexibility by introducing FACTS controllers enables a line to carry power closer to the thermal rating of the mechanical device [15]. This technology opened up new opportunities for controlling the power system problems like voltage instability or voltage collapse, decreasing the losses and enhancing the usable capacity of existing transmission lines [16]. In practice, it is desirable to 
optimize the deployment of reactive power sources, normally regarded to be in the voltage / var control domain and independent of active power related problems e.g. transmission line to ensure adequate system voltage performance [17].

It is against this background that this paper is aimed at investigating the voltage stability analysis of the Nigerian power system network. It uses the PSS/E software-based Newton-Raphson load-flow technique to evaluate the impact of renewable energy source (such as a wind generator) located on power system network with respect to the voltage variations.

\section{VOLTAGE STABILITY TECHNIQUES}

The voltage stability analysis can also be classified into static and dynamic analyses. Different methods have been reported in the literature for carrying out a steady - state voltage analysis. Power flow analysis is one of the techniques which are used to compute voltage magnitudes and phase angles at all buses. Other techniques include V-P curves, V-Q sensitivity analysis, Q-V modal analysis, Q-V curves and Minimum Singular Value methods etc. In the static analysis, the snapshot of the system is taken from different time instances in time domain trajectory, hence useful information such as voltage stability and proximity to voltage collapse can be derived. The use of static technique is good enough for analyzing voltage stability of a system. On the other hand, in the dynamic analysis, a series of first -order differential equations are derived and can be solved using any integration methods such as Euler method, RungKutta methods, numerical stability of explicit integration method or the implicit integration method [18]. In dynamic analysis sequence of events that causes voltage instability can be analyzed. Therefore, it is very vital to implement voltage instability analysis to ensure voltage level at all buses.

\section{MODELING OF RENEWABLE ENERGY SOURCE (WIND FARM GENERATOR)}

A wind turbine (WT) is a device that extracts kinetic energy from the air and feed it to a generator to generate electricity. The wind generator however, can impose limits on the power flow, voltage profile, power quality and electricity supplied to customers. As its penetration into the network increases, the influence on power quality and voltage stability becomes important. The wind turbine can be classified into five types [19].
- Type I: Fixed speed WT- with squirrel cage induction generator directly connected to the grid via step -up transformer.

- Type II: Limited variable speed WT with wound rotor induction generator.

- Type III: Variable speed WT with partial power electronic conversion and Doubly- Fed Induction generators (DFIG)

- Type IV: Variable speed with full power electronic conversion with both synchronous or induction generators and

- Type V: Variable speed with mechanical torque converter between low speed and high-speed shaft and synchronous generator.

Types I, III and IV are the most common types though the DFIG is widely used [19]. The advantages of using DFIG includes its ability to operate at variable wind speed, reduction in the cost of inverter, ability of controlling the quality of reactive power to be supplied or absorbed from the network and controlling the power factor. The figure 1.0 shows the schematic diagram of a DFIG [19].

From Figure 1, the stator is directly connected to the network whereas the rotor winding is connected to the network using back- to-back voltage source converter (VSC) and via slip rings. The VSC is able to deliver a variable frequency source while permitting a variable speed rotation. A constant voltage can be maintained at the stator by applying a voltage to the rotor winding that is proportional to the frequency. This implies the maintenance of the voltage-frequency $(\mathrm{v} / \mathrm{f})$ ratio constant. In [20] the steady static model of the DFIG is shown as in Figure 2. The subscript ' $d$ ' and ' $q$ ' refers to the direct and quadrature axis components.

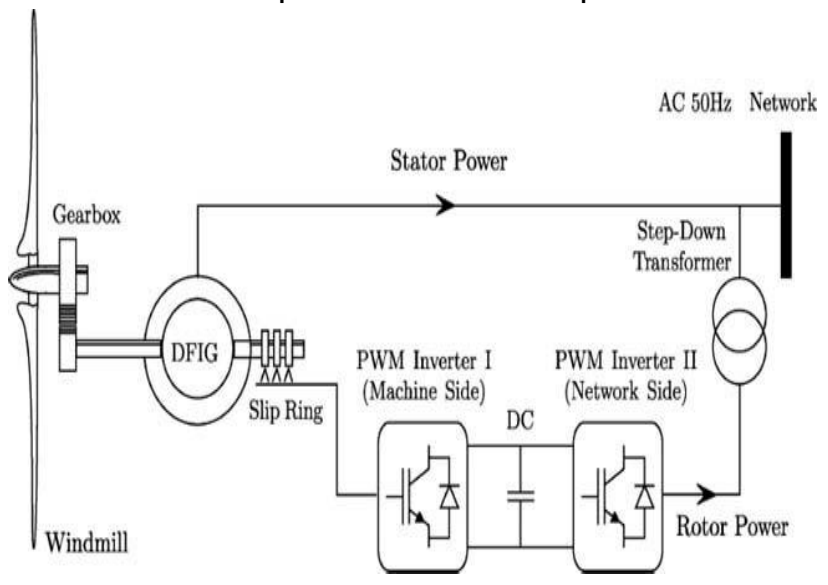

Fig. 1: Schematic diagram of a DFIG equipped with WT [19]

From the circuit, it is assumed that the stator and rotor flux dynamics are much faster compared to the 
grid dynamics. The converter decoupled the DFIG from the network.

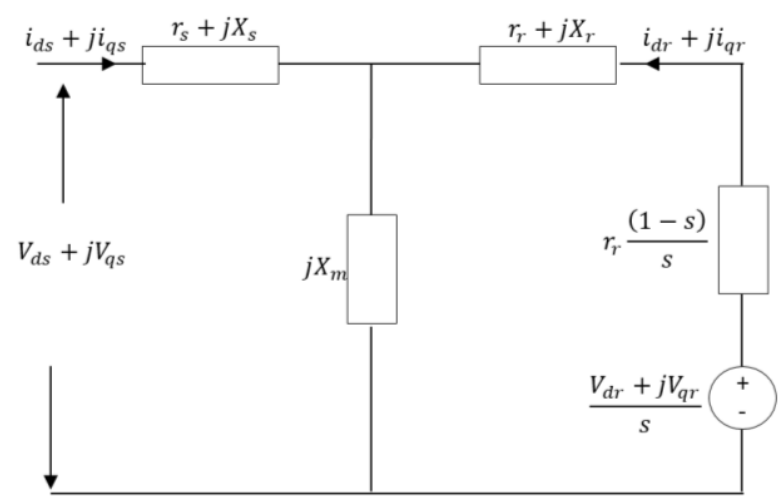

Fig. 2: The equivalent circuit (per phase) of the DFIG [20]

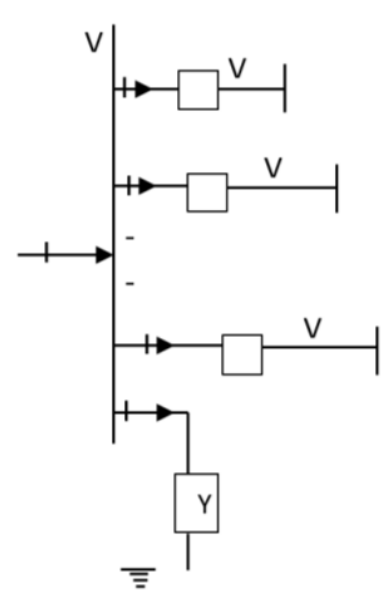

Fig. 3: A simplified th bus model of a power system

Under these assumptions, the stator circuit is represented by equations 1 and 2 as:

$$
\begin{aligned}
& V_{d s}=-r_{s} i_{d s}+\left(X_{s}+X_{m}\right) i_{q s}+X_{m} i_{q r} \\
& V_{q s}=-r_{s} i_{d s}-\left(X_{s}+X_{m}\right) i_{d s}+X_{m} i_{d r}
\end{aligned}
$$

Similarly, the rotor circuit is described by equations 3 and 4 as:

$$
\begin{aligned}
& V_{d r}=-r_{r} i_{d r}\left(1-\omega_{m}\right)\left(X_{r}+X_{m}\right) i_{q r}+X_{m} i_{q s} \\
& V_{q r}=-r_{r} i_{q r}-\left(1-\omega_{m}\right)\left(X_{r}+X_{m}\right) i_{d r}+X_{m} i_{q s}(4)
\end{aligned}
$$

When the losses are ignored, the per unit active power $(P)$ injected and reactive power $(\mathrm{Q})$ into the network becomes the sum of the stator and rotor powers and is given in equations 5 and 6 as:

However, there exists two types of control modes that can be applied to DFIG which include power factor control and voltage control mode. In the power factor control mode, the $\mathrm{P}$ and $\mathrm{Q}$ power of the stator are controlled to maintain constant voltage at the point of connection hence modeled as 'PQ bus' whereas in voltage control mode, the voltage is kept constant at the point of common coupling and is described as PV bus [21].

\section{POWER FLOW MODELING}

The load flow technique is required to obtain the steady-state solution of power system network and is as shown in Figure 3.

Hence equation (10), can be written as:

$$
\begin{gathered}
P=V_{d s} i_{d s}+V_{q s} i_{q s}+V_{d r} i_{d r}+V_{q r} i_{q r} \\
Q=V_{q r} i_{d s}-V_{d s} i_{q s} \\
I_{i}=I_{i 0}+I_{i 1}+I_{i 2}+\cdots+I_{i n} \\
I_{i}=y_{10} V_{i}+y_{i 1}\left(V_{i}-V_{1}\right)+y_{i 2}\left(V_{i}-V_{2}\right)+ \\
\cdots+y_{i n}\left(V_{i}-V_{n}\right) \\
I_{i}=\left(y_{10}+y_{i 1}+y_{i 2}+\cdots+y_{i n}\right) V_{i}-y_{i 1} \\
y_{i 2} V_{2}-y_{i n}
\end{gathered}
$$

In matrix representation, it becomes:

$$
\begin{aligned}
& {\left[\begin{array}{c}
I_{i} \\
. \\
I_{n}
\end{array}\right]\left[\begin{array}{llll}
y_{i 0}+y_{i 1}+y_{i 2} & -y_{i 1} & -y_{i 2} \cdots & y_{i n}
\end{array}\right]=\left[\begin{array}{l}
V_{i} \\
V_{1} \\
V_{2}
\end{array}\right]} \\
& Y_{i i}=y_{i 0}+y_{i 1}+y_{i 2}+\cdots .+y_{i n}
\end{aligned}
$$

where $Y_{i i}$ is referred to self-admittance while $y_{i 0}, y_{i 1}$ etc is referred as mutual admittance.

Hence equation (10), can be written as:

$I_{i}=Y_{i i} V_{i}+Y_{i 1} V_{1}+Y_{i 2} V_{2}+Y_{i n} V_{n}$ (11)

Equation (11) can equivalently be written as:

$$
I_{i}=Y_{i i} V_{i}+\sum_{\substack{K=1 \\ k \neq 1}}^{n} Y_{i k} V_{k}
$$

where $I_{i}$ is the current flowing into the bus $i_{\text {, }}$ $\mathrm{I}_{\mathrm{i} 0}$ the current flowing from bus $\mathrm{i}$ to ground, $I_{i 1}$ is the current flowing from bus $i$ to bus 1 , $\mathrm{I}_{\mathrm{i} 2}$ is the current flowing from bus $\mathrm{i}$ to bus 2 and In is the current flowing from bus $i$ to bus $n$, and the voltage at the respective buses is given as $V_{i}: V_{1}$ is the voltage at bus $1, V_{2}$ is the voltage at bus 2 while $V_{n}$ is the voltage at bus $n$.

$y_{i 0}$ is the admittance of transmission line between bus $i$ and ground,

$y_{i 1}$ is the admittance of transmission line between bus $i$ and bus 1 ,

$y_{i 2}$ is the admittance of transmission line between bus $\mathrm{i}$ and 2 and 
$y_{\text {in }}$ is the admittance of transmission line between bus $\mathrm{i}$ and bus $\mathrm{n}$.

The complex power injected at bus $\mathrm{i}$ is given as:

$$
S_{i}=P_{i-j} Q_{i}=V_{i}{ }^{*} I_{i}
$$

where $S_{i}$ is the apparent power injected at bus $i$,

$P_{i}$ is the real power injected at bus $i$,

$Q_{i}$ is the reactive power injected at bus $i$ and

$\mathrm{V}_{\mathrm{i}} *$ is the complex conjugate of bus i voltage.

Substituting equation (12) into (13) and re-arranged, we obtain:

$$
\frac{P_{i-j} Q_{i}}{V_{i}{ }^{*}}=Y_{i i} V_{i}+\sum_{\substack{K=1 \\ k \neq 1}}^{n} Y_{i k} V_{k}
$$

Making $V_{i}$ the subject in equation (14), we obtain

$$
V_{i}=\frac{1}{Y_{i i}}\left[\frac{P_{i-j} Q_{i}}{V_{i}{ }^{*}}-\sum_{\substack{K=1 \\ k \neq 1}}^{n} Y_{i k} V_{k}\right]
$$

Also, decoupling equation (15) into real and imaginary parts and expressing the components parts in polar form, we obtain equations (16) and (17):

$$
\begin{gathered}
P_{i}=\left|V_{i}\right|^{2} G_{i i}+\sum_{\substack{K=1 \\
k \neq 1}}^{n}\left|Y_{i k} V_{k} V_{i k}\right| \cos \left(\theta_{i k}+\delta_{k}-\delta_{i}\right) \\
Q_{i}=\left|V_{i}\right|^{2} B_{i i}+\sum_{\substack{K=1 \\
k \neq 1}}^{n}\left|Y_{i k} V_{k} V_{i k}\right| \cos \left(\theta_{i k}+\delta_{k}-\delta_{i}\right)
\end{gathered}
$$

where $G_{i i}$ is the self - conductance of bus $i$ and $B_{i i}$ is the self - susceptance of bus $i$.

Considering that the voltage at the buses must be within certain specified statutory limit, the voltage constraint at bus $i$ is then defined by equation (18):

$$
V_{i(\min )} \leq V_{i} \leq V_{i(\max )}
$$

where $V_{i(\min )}$ and $V_{i(\max )}$ are minimum and maximum values of voltage at bus $i$.

Since $P_{i}$ and $Q_{i}$ give a measure of the net real and reactive power at the bus i, they can be equivalently expressed by equations as:

$$
\begin{gathered}
P_{i}=P_{g i}-P_{i i} \\
Q_{i}=Q_{g i}-Q_{i i}
\end{gathered}
$$

where $\mathrm{P}_{\mathrm{gi}}$ is the real power supply at bus $\mathrm{i}$, $P_{i i}$ is the real power demand at bus $i$, $Q_{g i}$ is the reactive power supply at bus $i$ and $Q_{i i}$ is the reactive power demand at bus i.

The reactive power supply constraint at bus $i$ is specified by equation (21):

$$
Q_{g i(\min )} \leq Q_{g i} \leq Q_{g i(\max )}
$$

Where $\mathrm{Q}_{\mathrm{gi}(\min )}$ and $\mathrm{Q}_{\mathrm{gi}(\max )}$ are minimum and maximum values of reactive power supply at bus $i$. The power flow equations between the nodes $i-j$ after incorporating FACTS devices would appear as follows:

\section{For SVC:}

$$
\begin{gathered}
P_{j i}=V_{j}^{2} G_{i j}-V_{i} V_{j}\left(G_{i j} \cos \delta_{i j}+B_{i j} \sin \delta_{i j}\right) \\
Q_{j i}=-V_{j}^{2} G_{i j}+V_{i} V_{j} .
\end{gathered}
$$

For STATCOM: When STATCOM is shunt connected at bus $i$ and it is treated as var source, the power equation is modified and written as:

$$
\begin{aligned}
P_{i} & =P_{g i}+P_{S T C}-P_{i i} \\
Q_{i} & =Q_{g i}-Q_{S T C}-Q_{i i}
\end{aligned}
$$

\section{FORMULATION OF PROBLEM WITH FACTS DEVICES}

By definition, FACTS consists of power electronics devices and other static controllers that improve controllability and increase power transfer capability. Its optimal location and the network constraints is important to minimize the total operation cost at different loading conditions. Two objective functions are to be minimized, via the cost of energy and cost of investment of FACTS devices. The cost function for installation of some FACTS devices i.e. TCSC, SVC and UPFC are taken from [22] given as:

\section{For TCSC:}

$$
\begin{aligned}
& C F(T C S C)=0.0015\left(\text { TCSC }_{\text {value }}\right)^{2}- \\
& 0.7130\left(\text { TCSC }_{\text {value }}\right)+153.75(\text { US } \$ / \text { KVar })
\end{aligned}
$$

\section{For SVC:}

$$
\begin{aligned}
& C F(S V C)=0.0003\left(S V C_{\text {value }}\right)^{2}- \\
& 0.3051\left(S V C_{\text {value }}\right)+127.38\left(\frac{\text { US }}{\text { KVar }}\right)
\end{aligned}
$$

\section{For UPFC:}

$$
\begin{aligned}
& C F(U P F C)=0.0003\left(U P F C_{\text {value }}\right)^{2}- \\
& 0.2691\left(U P F C_{\text {value }}\right)+188.22\left(\frac{\text { US\$ }}{\text { KVar }}\right)
\end{aligned}
$$

Where TCSC value, SVC value and UPFC values are the operating values of the FACTS devices. The objective function comprises Energy Cost and FACTS costs and its optimization becomes the combinatorial where investment cost of FACTS devices is to be considered while minimizing transmission loss. So the objective function can be written as:

$$
C_{\text {Total cost }}=C_{\text {Energy }}+C_{\text {FACTS }}
$$

Where $C_{\text {Energy }}$ is the cost due to energy loss components and CFACTS is the investment cost of the FACTS devices. The following equality and inequality constraints of reactive, active and voltages nodal power should be satisfied. 


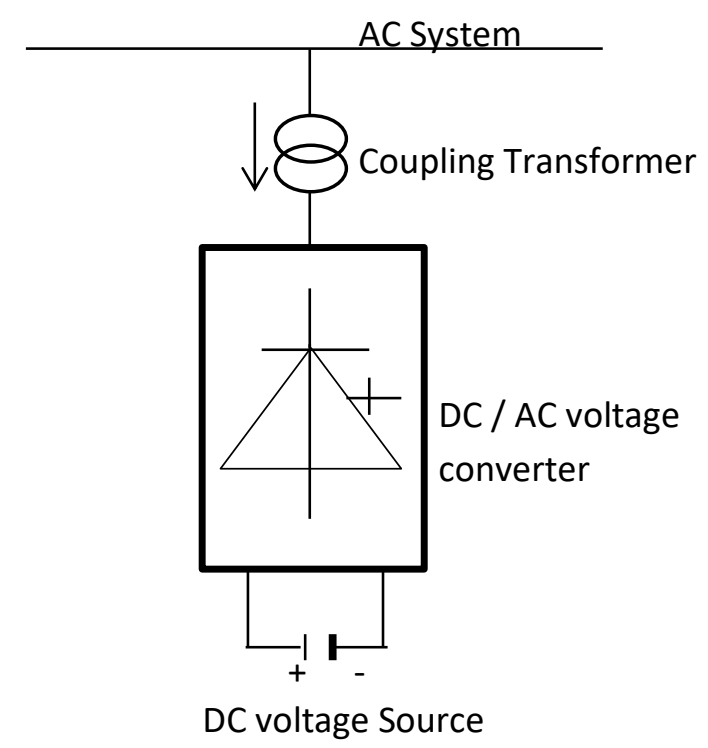

Fig. 4: A simple one-line diagram of STATCOM [23]

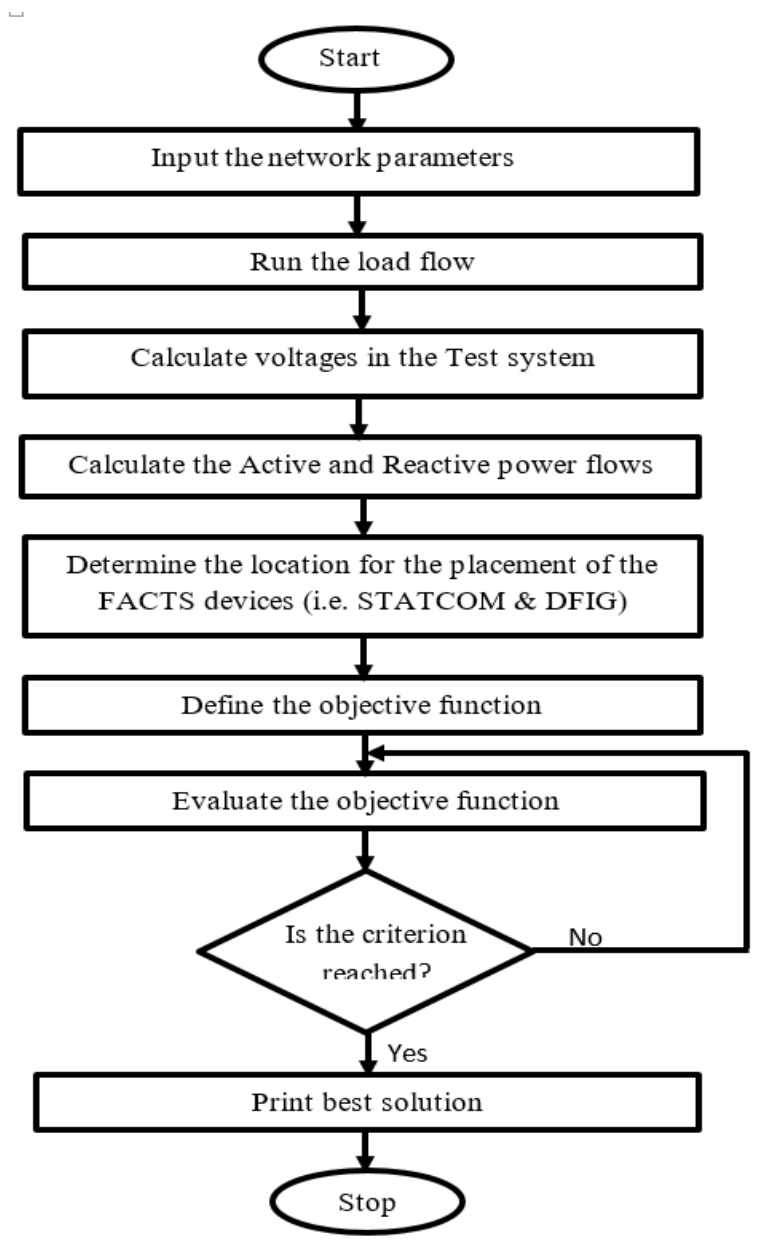

Fig. 5: Flow Chart of the proposed approach

It can be written within the limits as:

$$
\begin{gathered}
P_{n i^{\min }} \leq P_{n i} \leq P_{n i}{ }_{\max } \\
Q_{n i^{\min }} \leq Q_{n i} \leq Q_{n i^{\max }} \\
V_{i^{\min }} \leq V_{i} \leq V_{i^{\max }} \\
Q_{g^{\min }} \leq Q_{g i} \leq Q_{g i^{\max }}
\end{gathered}
$$

Where the superscripts min. and max. are the minimum and maximum limits of the variables

\section{FACTS PLACEMENT METHOD}

FACTS placement techniques are classified into three categories. These categories are the Artificial intelligence-based techniques, the Optimization-based methods and Sensitivity-based methods. In this paper, sensitivity based method was applied and STATCOM was used as reactive power compensators, to ensure that the voltages are within their statutory limits. STATCOM acts as current source or sink of reactive power and as a source of reactive power (Q) as shown in Figure 4. It comprises coupling transformer, voltage source inverter (VSI) and DC source. The arrangement is so to achieve control of reactive power flowing between the AC system and the STATCOM output. Then, if the amplitude voltage of the STATCOM is being regulated, reactive power $(\mathrm{Q})$ will be injected into the AC system or be absorbed from the AC system or neither injection nor absorption will occur. But, if the inverter output is being controlled, Active power (P) will be supplied to the AC System or withdrawn from the AC system [23]. The DC capacitor energy storage device is connected across the inverter to enable the STATCOM to control the power flow in a situation when the amplitude of the STATCOM is lower than the AC System voltage at the point of connection. Thereby absorbing the reactive power $(P)$ and producing reactive current when the STATCOM output voltage is greater than the AC system. By this it is expected that the system power transfer capability is maintained.

The STATCOM presents several advantages over other devices such as quick time response, small size, good dynamic characteristics under various operating conditions and accurate voltage control. The voltage source converter (VSC) is the main driving part of the STATCOM device. It consists of a self - commutating solid -state turn- off devices such as GTO and IGBT together with a reverse blocking diode in parallel. The IEEE Working Group of FACTS defines the SVC as a generator that can generate or absorbing reactive power when connected in parallel with a load, by so doing the voltage can be controlled.

Moreover, the placement of FACTS in the heavily loaded line is to decrease the reactive power flow and indirectly redistribute the additional power in other sections of lines to avoid their being overloaded. Effective control of reactive power compensation on weak buses improves voltage profile, reduces power 
loss and improves both steady state and dynamic performance of the system. The appropriate locations of FACTS devices in the power network are obtained based on the voltage stability index which is measured on each line for the same operating conditions [24].

\section{FORMULATION OF THE ALGORITHM}

The placement of these FACTS devices and DFIG is as shown in Figure 5.

\section{DISCUSSIONS AND RESULTS}

This study uses data collected from [26] which is an electrical power system network comprising twenty eight (28) buses, nine (9) generation stations and fifty two (52) transmission lines. Firstly, is the solution of the power flow problem using the full Newton Raphson iterative technique in PSS/E software. The result of the simulation is shown in Table 1 . The result also shows that ten (10) buses out of the twenty - eight (28) buses fall-out of the statutory limit of $0.95 \leq V_{i} \leq 1.05$ and the total MW and MVAr and power loss obtained is as shown in Table 2. This result is termed CASE I.
Secondly, the application of FACTS (STATCOM) and DFIG devices to one of the weakest bus, i.e. bus 16 . The connected wind turbine generation operates as a $\mathrm{PQ}$ bus with unit power factor.

The result shows an improvement in the voltage magnitude, MW, MVAr and power losses leaving only about four (4) buses out of statutory voltage limit. The result is termed CASE II and presented in Table 2.

Thirdly, the application of the same FACTS (STATCOM) and DFIG devices added to the next weakest bus, bus 22. The result showed tremendous improvement in the voltage magnitude of all the buses as well as MW, MVAr power losses of the buses to approximately 1.0 per unit value, from $161.0 \mathrm{MW}$ to $130.8 \mathrm{MW}$ and 1205.8 MVAr to 978.9 MVAr respectively. These results revealed that there was a general improvement in the bus voltages and transmission capability of active power (MW) by the inclusion of FACTS devices (STATCOM) and DFIG on appropriate buses. This result is then termed CASE III. These results are shown in Figures 7, 8 and 9.

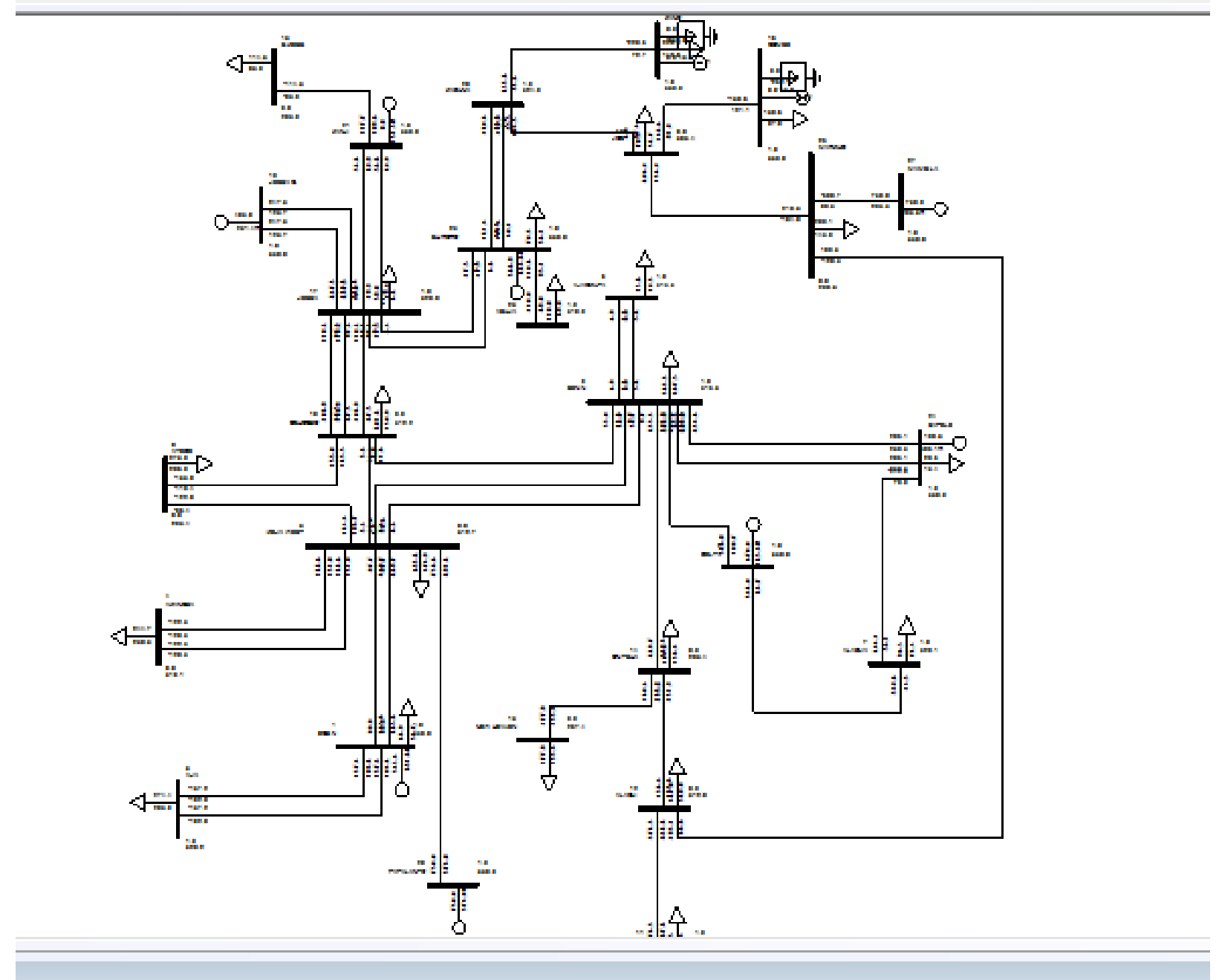

Fig. 6: The 28 - buses power system network with FACTS and DFIG 
Table 1: Results of simulation

\begin{tabular}{|c|c|c|c|c|c|}
\hline $\begin{array}{l}\text { Bus } \\
\text { Number }\end{array}$ & Bus Name & $\begin{array}{l}\text { Cod } \\
\text { e }\end{array}$ & $\begin{array}{l}\text { Voltage (Pu) (CASE } \\
\text { I) }\end{array}$ & $\begin{array}{l}\text { Voltage (Pu) (CASE } \\
\text { II) }\end{array}$ & $\begin{array}{l}\text { Voltage (Pu) (CASE } \\
\text { III) }\end{array}$ \\
\hline 1 & EGBIN & 3 & 1 & 1 & 1 \\
\hline 2 & DELTA & 2 & 1 & 1 & 1 \\
\hline 3 & AJA & 1 & 0.9946 & 0.9946 & 0.9946 \\
\hline 4 & AKANGBA & 1 & 0.9396 & 0.9397 & 0.9397 \\
\hline 5 & IKEJA WEST & 1 & 0.9474 & 0.9475 & 0.9475 \\
\hline 6 & AJAOKUTA & 1 & 0.9555 & 0.9555 & 0.9554 \\
\hline 7 & ALADJA & 1 & 0.9942 & 0.9942 & 0.9942 \\
\hline 8 & BENIN & 1 & 0.9586 & 0.9591 & 0.9591 \\
\hline 9 & AYEDE & 1 & 0.8951 & 0.8951 & 0.8951 \\
\hline 10 & OSHOGBO & 1 & 0.9462 & 0.9462 & 0.9462 \\
\hline 11 & AFAM & 2 & 1 & 1 & 1 \\
\hline 12 & ALAOJI & 1 & 0.9374 & 0.9447 & 0.9448 \\
\hline 13 & $\begin{array}{l}\text { NEW } \\
\text { HEAVEN }\end{array}$ & 1 & 0.8053 & 0.8099 & 0.8099 \\
\hline 14 & ONITSHA & 1 & 0.8643 & 0.8643 & 0.8643 \\
\hline 15 & B/KEBBI & 1 & 0.8903 & 0.8903 & 0.8903 \\
\hline 16 & GOMBE & 1 & 0.5967 & 1 & 1 \\
\hline 17 & JEBBA & 1 & 0.997 & 0.997 & 0.997 \\
\hline 18 & JEBBA G. & 2 & 1 & 1 & 1 \\
\hline 19 & JOS & 1 & 0.776 & 0.9056 & 0.9051 \\
\hline 20 & KADUNA & 1 & 0.9253 & 0.9516 & 0.9515 \\
\hline 21 & KANJI & 2 & 1 & 1 & 1 \\
\hline 22 & KANO & 1 & 0.7514 & 0.7868 & 0.7866 \\
\hline 23 & SHIRORO & 2 & 1 & 1 & 1 \\
\hline 24 & SAPELE & 2 & 1 & 1 & 1 \\
\hline 25 & ABUJA & 1 & 0.9692 & 0.9692 & 0.9692 \\
\hline 26 & MARKUDI & 1 & 0.8068 & 0.8674 & 0.8671 \\
\hline 27 & MAMBILA & 2 & 1 & 1 & 1 \\
\hline 28 & PAPALANTO & 2 & 1 & 1 & 1 \\
\hline
\end{tabular}

Table 2: Results

\begin{tabular}{lcccccc}
\hline & \multicolumn{2}{c}{ CASE I } & \multicolumn{2}{c}{ CASE II } & \multicolumn{2}{c}{ CASE III } \\
\hline & MW & MVAr & MW & MVAr & MW & MVAr \\
\hline Generated power & 4225.4 & 4223.4 & 4218.0 & 3822.8 & 4218.6 & 3567.4 \\
Load & 4064.4 & 3017.6 & 4071.8 & 3023.1 & 4071.8 & 3023.1 \\
Induction Motor & - & - & 8.0 & 43.2 & 16.0 & 86.3 \\
FACTS Devices & - & - & 0.0 & 278.6 & 0.0 & 520.9 \\
Power Losses & 161.0 & 1205.8 & 138.2 & 1035.1 & 130.8 & 978.9 \\
\hline
\end{tabular}




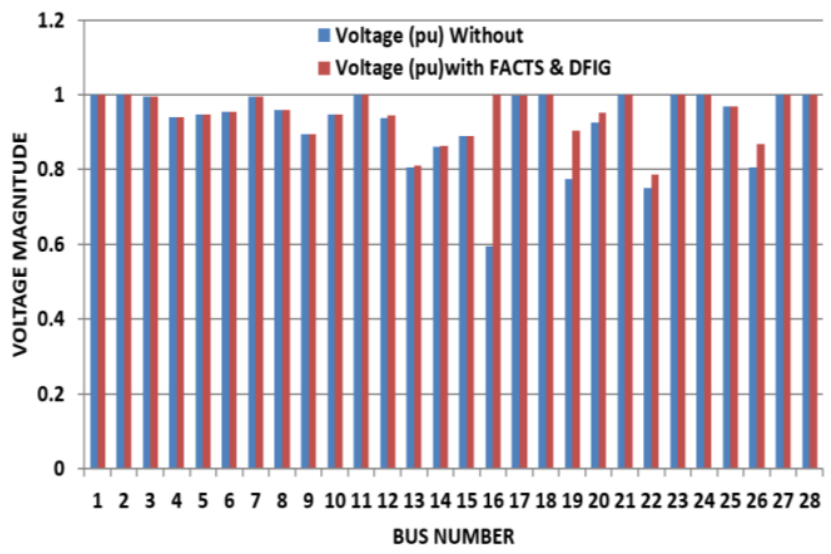

Fig. 7: Voltage magnitude of the test network system (Case I \& Case II)

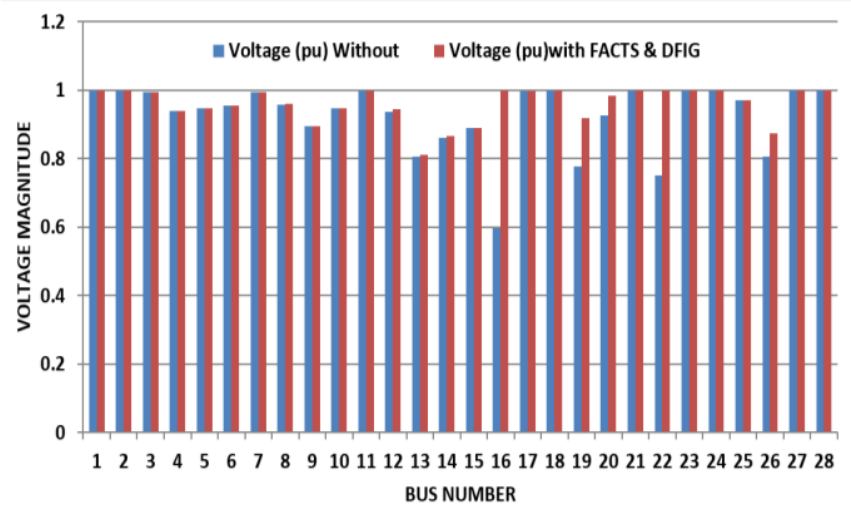

Fig. 8: Voltage magnitude of the test network system (Case I \& Case III)

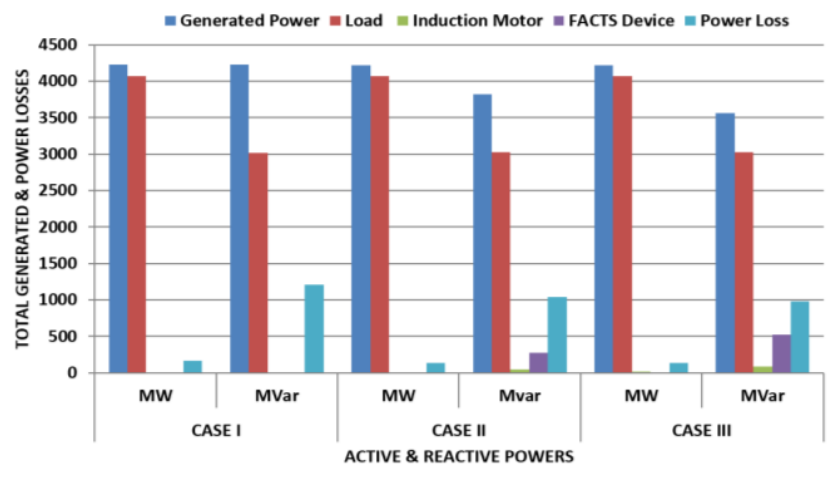

Fig. 9: Test Network Power system values

\section{CONCLUSION}

The voltage stability analysis of the Nigerian $330 \mathrm{kV}$, 28-bus, 52-transmission line and 9-generation station has been reported in this paper. For proper and uninterruptible operation of the power system network, equipment protection and voltage stability, it is crucial to deal with voltage instability conditions. If not rectified in time, it may result in total blackout which may stay for days. This work gives an overview of voltage stability phenomenon with wind farms and FACTS devices (STATCOM). It shows an improvement in voltage magnitudes with reduction in active and reactive power losses to about $18.8 \%$ in each case. The results show that the application of STATCOM and DFIG devices to the network has the capability to avoid voltage collapse or voltage instability of the Nigerian power system.

\section{REFERENCES}

[1]. C.W. Taylor, Power System Voltage Stability, McGraw- Hill, 1994

[2]. A. O. Ekwue, H.B. Wan, D.T.Y. Cheng, Y.H. Song, "Voltage Stability analysis on the NGC System", Electric Power Systems Research Journal, 47, 1998, 173-180.

[3]. Raoufi H., Kalantar M., "Reactive Power Scheduling with generator ranking for voltage stability improvement", Energy Conservation Management, 2009, 50(4), 1129-1135

[4]. IEEE Committee Report Voltage Stability of Power Systems Concepts, Analytical Tools and Industry Experience, IEEE Publication $90^{\text {th }} 358$ 2 PWR New York, 1990

[5]. Bindeshwar Singh N.K., Sharma Rajkumar, A.N. Tiwari,"Prevention of voltage instability by Using FACTS Controllers in Power System A literature Survey" International Journal of Engineering Science and Technology, 2010, vol. 2(5) 980-992

[6]. A.O. Ekwue, H.B. Wan, D.T.Y. Cheng, Y.B. Song, "Singularity value decomposition method for voltage stability analysis on the National Grid System", Electric Power and Energy System Research Journal, 211999 425-432

[7]. Mobarak Y A, "Voltage Collapse Prediction for Egyptian Interconnected Electrical Grid, EIEG, International Journal on Electrical Engineering and Informatics, 2015, (1)7,pp. 79-88

[8]. Rozlan M.B., M. Zobaa, A.F. Abdel, Aleem, S.H.E. "The Optimization of Stand Alone Hybrid Renewable Energy Systems using HOMER", Int. Rev. Elect. Eng. 2011, vol. 6, 1802-1810

[9]. Kevin Zibran Heetun, Shady H.E. Abdel Aleem \& Ahmed F. Zobaa, "Voltage stability analysis of grid-connected wind farms with FACTS and dynamic analysis", Energy and Policy Research, 2016, 3:1, 1-12

[10]. Linh Nguyen Tung, "Voltage Stability analysis of grids connected wind generators", IEEE Xplore Conference, June 2009. 
[11]. R.A. Jokojeje, I.A. Adejumobi, A.O. Mustapha and O.I. Adebisi, "Application of Static Synchronous Compensator (STATCOM) in improving Power system performance, A case study of the Nigeria 330KV electricity grid", Nigeria Journal of Technology 2015, vol.34 no 3, pp $564-572$

[12]. Esther Barrios Martinez, Cesar Angeles Camacho, "Technical comparison of FACTS controllers in parallel connection", Journal of Applied Research and Technology, 2017, (15), 36-44

[13]. Higorani N.G, "High Power Electronics and Flexible AC Transmission System", IEEE Power Eng. Rev. 1998

[14]. Baker M.H. "An Assessment of FACTS controllers for Transmission System Enhancement" CIGRE SC 14 International Colloquium on HVDC \& FACTS, Montreal 1995.

[15]. S. Tara, Kalyani G., Tulasiram Das, "Simulation of Real and Reactive Power Flow Control with UPLC connected to a transmission line", Journal of Technical and Applied Information Technology. 2008.

[16]. A Kazemi, S. Jamali, M. Habibi and S. Ramezan Jamant, "Optimal location of TCSCs in a Power System by Means of Genetic Algorithms considering loss Reduction" First International Power and Energy Conference (2006), pp 134 139

[17]. H.B. Wan, M.E. Bradley, A.O. Ekwue and A.M. Chebbo, "Method for alleviating voltage limit violations using combined Dc optimization and A.C power flow technique", IEE Proceedings on Generation, Transmission. Distribution, March 2000, vol. 147, No 2
[18]. Milano F., "An open source power system Analysis Toolbox, IEEE Trans. Power Sys. 2005, vol. 20, pp 1199-1206.

[19]. Zhang Y., Ula S., "Comparison and Evaluation of three main types of wind turbines", IEEE /PES Transmission and Distribution Conference and Exposition, 2008, pp 1-6

[20]. Simani S., Farsoni S, Castaldi P. "Wind Turbine Simulator Fault Diagnosis via Fuzzy modeling and identification Techniques", Sustainable Energy Grids Networks, 2015, vol.1, 45-52

[21]. Guleryuz M., Demiroren A., "Effects of a Wind Farm and FACTS devices on static voltage stability of Bursa Transmission System in Turkey", $10^{\text {th }}$ International Conference on Environmental and Electrical Engineering (EEEIC), 2011, pp 1-5

[22]. H.I. Shaheem, G.I. Rasheed, and S.J. Cheng, "Optimal Location and Parameters Setting of Unified Power Flow Controller Based on Evolutionary Optimization Techniques", IEEE PES General Meeting, 2007, pp. 1-8

[23]. Edvina, U. Claudio, A.C and John, R. "Fundamental frequency model of static synchronous compensator", North American Power System Symposium (NAPS), Laramie, Wyoming, 1997, 49-54.

[24]. Cai L, Erlich I. "Optimal choice and allocation of FACTS devices using genetic algorithms", In Proceedings on Twelfth Intelligent Systems Application to Power Systems Conference, 2003, pp. 1-6

[25]. Gupta J.B, A Course in Power System, New Delhi, India, S.K. Katari and Sons publisher. 2011

[26]. Transmission Company of Nigeria Control Centre, Oshogbo, South Western, Nigeria, 2013 